Int. J. Curr. Res. Med. Sci. (2016). 2(10): 60-64

OP

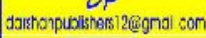

It.

DARSHAN

PUBLISHERS

wrm.dashano.bishers.con
International Journal of Current Research in Medical Sciences

ISSN: 2454-5716

www.ijcrims.com

Volume 2, Issue 10 -2016

\title{
Krukenberg Tumour of the Ovary in young Female: A Case Report.
}

\section{Dr Amit Kumar Nirmal ${ }^{1 *}$, Dr. Kirti Nirmal ${ }^{2}$, Dr.Sudhir Kumar ${ }^{3}$ and Dr Jaykant Jha ${ }^{4}$}

${ }^{1}$ Post Graduate III ${ }^{\text {rd }}$ year, Department of Pathology, Saraswathi Institute of Medical Sciences Hapur (U.P).

${ }^{2}$ Senior Resident, Department of Microbiology, University College of Medical Sciences and Guru Tag

Bahadur Hospital, East Delhi 110095.

${ }^{3}$ Senior resident, Department of Pharmacology, Hindu Roa Hospital and Medical Collage,

North Delhi Municipal Corporation, Malka Ganj, New Delhi 110007.

${ }^{4}$ Professor, Department of Pathology, Saraswathi Institute of Medical Sciences, Hapur (U.P).

*Corresponding Author- Amit Kumar Nirmal, Post Graduate III ${ }^{\text {rd }}$ year

Department of Pathology, Sarasvati Institute of Medical Sciences, Hapur (U.P)

E-mail: doctoramitkumarnirmal@gmail.com

\section{Abstract}

Krukenberg tumor is an interesting and rare clinical entity. It is an uncommon metastatic tumour of the ovary with transcoelomic spread and accounts for 1-2 \% of all ovarian tumours. It is usually but not always a bilateral involvement of ovaries from metastatic deposit from adenocarcinoma of stomach and rarely from other gastrointestinal (GI) and non GI organs. Stomach is the most common primary site, but other organs can serve as a primary site. The occurrence of a Krukenberg tumor in young individuals is rare, with only few cases reported in the second decade of life. Accurate diagnosis of Krukenberg tumor requires thorough endoscopic and histopathological examination to exclude primary ovarian tumors. Herein, we report a rare case of a 36 year old woman who presented with bilateral ovarian masses. Total hysterectomy with bilateral salpingo-oophorectomy was performed. Histopathological examination confirmed the diagnosis of Krukenberg tumor.

Keywords: Krukenberg tumour, ovarian mass.

\section{Introduction}

Krukenberg tumour, an uncommon metastatic tumour of the ovary, originates in the stomach in the vast majority of cases. (Kiyokawa T, 2006). Metastatic involvement of the ovaries is not a rare event in adult cancers and 5-30\% ofovarian cancers are metastatic malignancies. It is bilateral in $80 \%$ of the cases. (Young RH 2006). Approximately $5 \%$ of all carcinomas metastatic to the ovaries are adenocarcinoma with pleomorphic mucin filled signet ring cells, firstly reported by Friedrich Ernst Krukenberg in 1896, and therefore named Krukenberg tumour.(F. Krukenberg, 1896) 
In this tumour, the most frequent site of the primary is the stomach $(70 \%$ of the cases), followed by large bowel, appendix and, occasionally, a variety of other locations.(R.H. Young, 2002,J.Prat, 2005) On occasions, the gastric cancer may be small and remains undetected for several years after oophorectomy. (Kiyokawa T, 2006: Al-Algha OM et al, 2006) However, in a quarter of the cases, the primary tumor is very small and can escape detection. The involvement of the ovary, which is most commonly bilateral and can reach huge proportions, is thought to be the consequence of selective retrograde lymphatic spread of the primary tumor along the stomach ovarian axis.(R.H. Young, 2007) Since no effective treatment has been identified, patients diagnosed with Krukenberg tumor usually have a fatal outcome, with a median survival time of 14 months.(Al-Algha OM et al, 2006) In this report, we describe a case of a 31-year-old woman with bilateral Krukenberg tumour.

\section{Case Report}

A 31 years old female presented with fullness of lower abdomen. The patient complained of low back pain and menstrual irregularity since 2 months. She had no family history of any malignancy. Ultrasound revealed bilateral large well defined mass lesions with heterogeneous solid and cystic components in both uterine adnexa. In addition, there was gross ascites. Possibility of bilateral malignant ovarian tumours was suggested. Serum levels of CA-125 were raised $(140 \mathrm{U} / \mathrm{ml})$ Patient underwent total abdominal hysterectomy with bilateral salpingooophorectomy (TAH with BSO).

On gross examination the ovarian tumours measured $15 \times 9 \times 10 \mathrm{cms}$ and $17 \times 11 \times 7.5 \mathrm{~cm}$ in size respectively. Both ovarian tumours showed bosselated outer surface with one ovary showing presence of few cysts on the surface. Cut surface was solid, firm, grey white and lobulated with one of the ovaries showing few cysts filled with serous fluid.

Microscopic examination of multiple sections from both the ovaries showed tumour cells arranged in clusters, tubules and small glands as well as individually infiltrating the densely cellular to oedematous stroma. The tumour cells had high nucleo-cytoplasmic ratio, pleomorphic nuclei and moderate to abundant cytoplasm. Many signet ring cells were seen and their cytoplasm varied from pale, vacuolated to eosinophilic and granular.

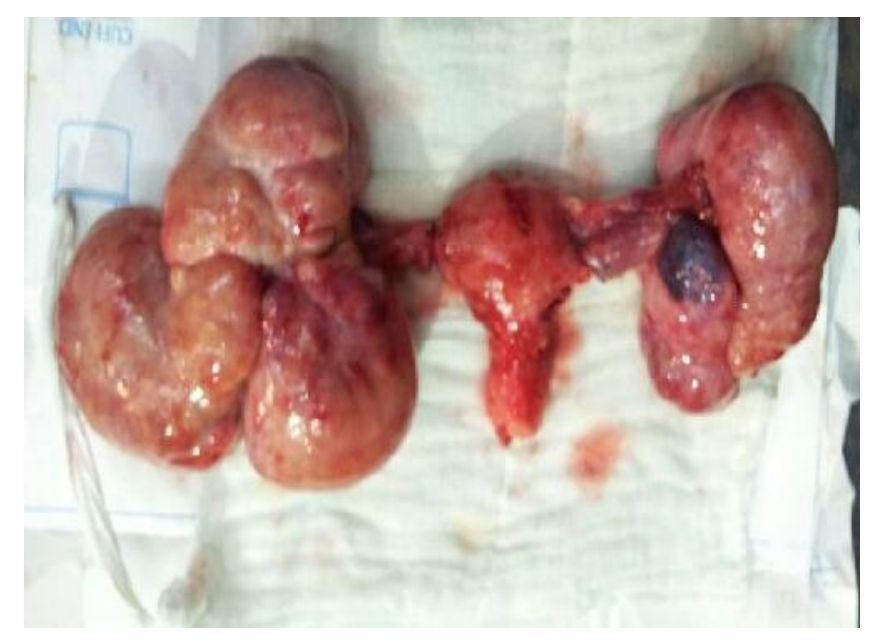

Fig 1. Photograph of Bilateral Ovarian Tumours with Boss elated Outer Surface. 


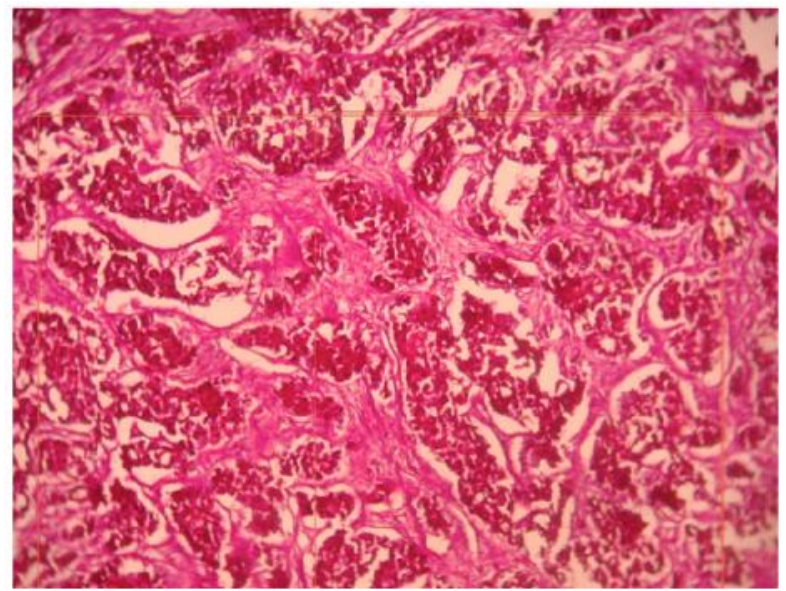

Fig 2: Photomicrograph Showing Mucin Positive cells Signet Ring Cells. (PAS with diastase, 10X).

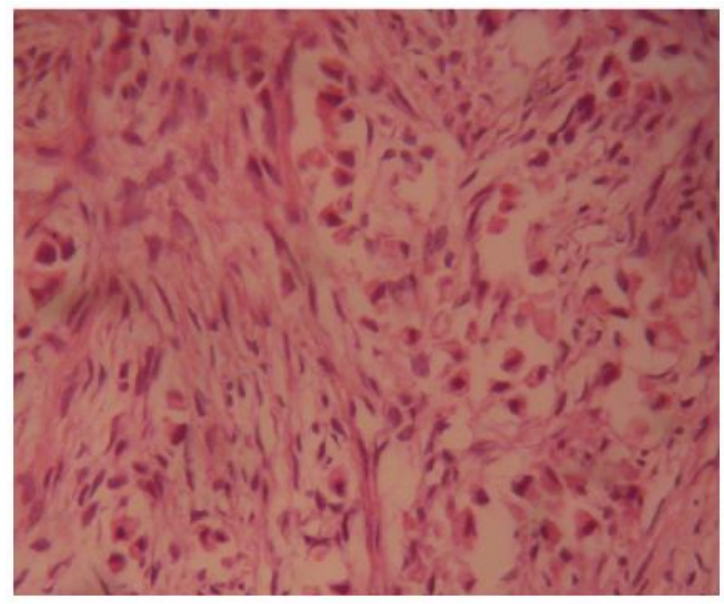

Fig 3: Photomicrograph showing Tumour including signet Ring cells (H\& E, 40X).

\section{Discussion}

Krukenberg tumour is a metastatic signet ring cell adenocarcinoma accounting for $1 \%$ to $2 \%$ of all ovarian tumours (Mates IN et al, 2008) usually presented in younger female with average age of 45 years. (Young RH, 2006: Al-Algha OM et al, 2006) Most of the cases originate from gastric adenocarcinoma. Patients usually present with symptoms related to ovarian involvement such as abdominal pain and distension. Ascites is usually present in $50 \%$ of cases. (Al-Algha OM et al, 2006) Majority of cases they aresynchronous, but $20 \%$ to $30 \%$ occur as metachronous lesion after removal of primary. Stomach is the primary site in most Krukenberg tumours followed by carcinomas of colon; appendix and breast are the next common primary sites. As the tumor is usually well encapsulated and rarely shows any ovarian surface involvement, theory of peritoneal seeding from primary lesion is questioned. Rich lymphatics draining gastric mucosa and submucosa initiating retrograde lymphatic spread to ovary is mostly accepted theory. Few authors favour theory of haematogenous spread through thoracic duct. (Taylor AE, 1995) The prognosis of a patient with Krukenberg tumor is extremely poor with average survival time between 3 and 10 months. Only $10 \%$ of patients survive more than two years after diagnosis. (Yook JH et al, 2007)

Treatment of patients with Krukenberg tumor is controversial. Some studies have investigated the role of removing Krukenberg tumor originated from stomach and demonstrated that resection of ovarian metastases might prolong survival. (McGill FM et al, 1999) Some other studies suggested that metachronous ovarian metastases 
or unilateral ovarian metastases might correlate with good survival and ovarian metastasectomy may be beneficial when gross residual diseases being thoroughly eradicated.(Jun SY et al,2011) Our patient was originally a case of gastric adenocarcinoma with synchronous Krukenberg tumor. Patient underwent total abdominal hysterectomy with bilateral salpingooophorectomy, without the knowledge of having a gastric lesion.

The microscopic spectrum of Krukenberg tumour is very broad and tubules, glands and cysts are often present. Moreover the microscopic examination shows a great variation from case to case and also within the individual neoplasm. The cellularity of the stroma varies from densely cellular to paucicellular and the paucicellular areas ranging from oedematous to mucoid. Signet ring cells are seen in most neoplasms but are often absent orinconspicuous in significant areas. The signet ring cells vary widely in their arrangement, growing singly, in clusters, pseudo tubular arrays or as lining of true tubules. Small glands and tubules are common, often resembling microcysts (when the lining is flattened) or sertoli tubules. (Kiyokawa T, 2006) Although the entity of primary Krukenberg tumour cannot be denied, all women with typical Krukenberg tumours should be considered as having metastatic carcinoma until proved otherwise (Holtz F et al, 1982) The prognosis of patients with Krukenberg tumour is extremely poor with average survival time between 3 to 10 months. Only 10\% of patients survive more than 2 years after diagnosis. (Das $\mathrm{S}$ et al, 2014)

\section{Conclusion}

It is important to be familiar with diagnostic histopathological features of Krukenberg tumour for correct diagnosis and prevention of tumour misclassification.

\section{References}

1. Kiyokawa $\mathrm{T}$ et al: Krukenberg tumours of the ovary: a clinicopathologic analysis of 120 cases with emphasis on their variable pathologic manifestation. Am J Surg Pathol 30: 277-299, 2006.

2. Young RH (2006) From Krukenberg to today: the ever present problems posed by metastatic tumors in the ovary: part I. Historical perspective, general principles, mucinous tumors including the Krukenberg tumor. Adv Anat Pathol 13(5): 205-227.

3. F. Krukenberg Uber das fibrosarcoma ovarii mucocellulare (Carcinomatodes) Arch Gynecol, 50 (1896), pp. 287-321.

4. R.H. Young, et al Scully Metastatic tumors of the ovary R.J. Kurman (Ed.), Blaustein's pathology of the female genital tract (5th ed.), Springer, New York (2002), pp. 1063-1101.

5. J.Prat et al Ovarian carcinomas, including secondary tumor: diagnostically challenging areas Mod Pathol, 18 (Suppl. 2) (2005), pp. S99-S111.

6. Al-Algha $\mathrm{OM}$ et al: An in-depth look at Krukenberg tumor. Arch Pathol Lab Med 130: 1725-1730, 2006.

7. R.H. Young from Krukenberg to today: the ever present problems posed by metastatic tumors in the ovary Adv Anat Pathol, 14 (2007), pp. 149-177.

8. Mates IN et al Features of Krukenberg type tumours - clinical study and review. Chirurgia 2008; 103(1): 23-28.

9. Taylor AE, et al Ovarian metastases from primary gastrointestinal malignancies: the Royal Marsden Hospital experience and implications for adjuvant treatment. $\mathrm{Br} \mathrm{J}$ Cancer 1995 71:926.

10. Yook JH et al Clinical prognostic factors for ovarian metastasis in women with gastric cancer. Hepatogastroenterology 2007 54:9559.

11. McGill FM et al. Krukenberg tumors: can management be improved? Gynecol Obstet Invest 1999 48:615. 
12. Jun SY et al Metachronous ovarian metastases following resection of the primary gastric cancer. J Gastric Cancer 2011 11:317.

13. Holtz $\mathrm{F}$ et al Krukenberg tumors of the ovary: a clinicopathological analysis of 27 cases. Cancer 1982; 50: 2438-47.

14. Das $\mathrm{S}$ et al. A curious discourse of Krukerberg tumor. A case report. J Gastrointest Oncol 2014; 5(6): E 117 - E 120.

\begin{tabular}{|c|l|}
\hline \multicolumn{2}{|c|}{ Access this Article in Online } \\
\hline Q & Website: \\
\hline & www.ijcrims.com \\
\hline Quick Response Code & Subject: \\
\hline
\end{tabular}

\section{How to cite this article:}

Amit Kumar Nirmal, Kirti Nirmal, Sudhir Kumar and Jaykant Jha. (2016). Krukenberg Tumour of the Ovary in young Female: A Case Report.. Int. J. Curr. Res. Med. Sci. 2(10): 60-64.

DOI: http://dx.doi.org/10.22192/ijcrms.2016.02.10.006 